\title{
Identity Construction of Female Consumers in Chinese and American Cosmetics Advertisements: A Critical Pragmatic Study
}

\author{
Siyun Huang ${ }^{1}$ \\ ${ }^{1}$ School of English for International Business, Guangdong University of Foreign Studies, Guangzhou, China \\ Correspondence: Siyun Huang, School of English for International Business, Guangdong University of Foreign \\ Studies, No.2 Baiyundadaobei, Guangzhou, 510420, P. R. China. Tel: 0086-135-3328-4910. E-mail: 1220857180 \\ ${ }^{\circledR}$ qq.com
}

Received: December 11, 2020; Accepted: December 22, 2020; Published: December 24, 2020

\begin{abstract}
At present, women are still the main force among cosmetics consumers. In order to stimulate female consumers' desire to buy cosmetics, cosmetics advertisers strive to build identities for female consumers that they are deeply yearning for, so as to guide and entice female consumers to buy their products. From the perspective of critical pragmatics, this study focuses on the types, distribution, means, and purposes of identity construction in Chinese and American advertisements, and conducts qualitative and quantitative analysis on cosmetic advertisements. Through contrastive analysis, it reveals the types and frequency of identity, and pragmatic strategies, motivation of advertisers in China and America. These identities are used to attract consumers to purchase behavior. When constructing these identities, cosmetics advertisers adopt explicit and implicit means to make psychological hints to female consumers. This study criticizes and analyzes the marketing motives of advertisers from the perspective of pragmatic identity theory, thereby revealing consumption traps for female consumers, and providing new thinking for identity construction and marketing strategies.
\end{abstract}

Keywords: identity construction, cosmetics advertising, critical pragmatic analysis, female consumers

\section{Introduction}

Cosmetic plays an important role in women's daily life. Cosmetics are industrial chemicals that can be applied to any part of the human body to make it look better. As a communication medium, advertisements can effectively play the role of information transmission and persuasion (Yang, 2020). The purpose of cosmetics advertisement is to persuade consumers to spend a large amount of money to buy cosmetics. Since women are still the main force in cosmetics consumption, this paper focuses on the identity construction of female consumers. Therefore, cosmetics advertisements full of persuasion techniques are worth studying.

Cosmetics advertising attracts the attention of language researchers because of its linguistic features and pragmatic strategies. At present, the study of cosmetics advertising includes translation (Cai, 2020; Pan \&Hu, 2020), corpus linguistics (Yang, 2020), systemic functional linguistics (Yu, 2020) and pragmatics (Zhong, 2016; Xiong, 2019). At present, some researchers have found that cosmetics advertisers tend to cater to consumers' demands for particular identities (Zhong, 2016), but there is no literature to analyze it further from the perspective of identity construction. Some scholars have studied female image in cosmetics advertising (Zhong, 2016; Ji, 2019), but they seldom do research from the perspective of critical pragmatics. To fill the research gap, the study focuses on critical pragmatic analysis of the identity construction of female consumers in Chinese and American cosmetics advertisements. Studying the identity construction of cosmetics advertisements can strengthen female consumers' understanding of advertising language and reveal their persuasion strategies and ideologies so as to remind consumers of rational consumption. Therefore, from the perspective of critical pragmatic analysis, this study finds out the similarities and differences between Chinese and American cosmetics advertisements and the identities constructed to persuade females to buy cosmetics. This study is structured as follows: the following section will review previous researches on cosmetics advertising and point out research gaps. The methodology adopted in the research and results will be introduced in the third and fourth sections. After analysis, the reasons why advertisers adopt such pragmatic means will be discussed in detail. 


\section{Literature Review}

\subsection{Pragmatic Identity}

Identity research is the center stage of the social sciences (Bamberg, De Fina \& Schiffrin, 2007; Kroskrity, 1999), and it is also a current hot topic in the humanities and social sciences (Chen, 2013). Pragmatic identity refers to the fact that a person, especially the speaker and the listener, presents true or untrue in a specific context with a specific social identity. It is the result of the communicator's choice when he or she gives or understands a specific speech or text. The other identities of social individuals or groups mentioned in discourse are collectively called pragmatic identities (Chen, 2013; Chen, 2014). The view of identity from the perspective of pragmatics believes that various identities do not play roles in communication at the same time, and only the identities that are activated in the current context are the identities that affect the current discourse (Chen, 2004).

In addition, pragmatic identity is a pragmatic content that focuses on the relationship between the speaker and the symbol. Pragmatic theories, such as politeness theory and adaptation theory, can provide a starting point for the systematic study of pragmatic identity. Different from the study of identity from the perspectives of sociology, psychology and communication, the study of identity from the perspective of pragmatics focuses on the communicative or pragmatic attributes of identity. To develop identity research from a pragmatic perspective, the following five aspects need to be explored (Chen, 2018b): 1) the influence of specific identity construction on the generation and understanding of language meaning; 2) the influence of specific identity construction on communication needs; 3 ) the influence of specific identity construction on the understanding and expression of interpersonal meaning; 4) the influence of specific identity construction on the choice of a particular language style; 5) the influence of specific identity construction on the appropriateness of particular language use. It should be emphasized that studying identity from the perspective of pragmatics is not only to study the identity types constructed by cosmetics advertisers for female consumers. In other words, the choice and construction of identity is only a research means rather than a research objective. To study identity from the perspective of pragmatics, we should not only focus on the types and frequency of identity construction, but also pay more attention to figuring out why cosmetics advertisers construct these identities and how they achieve marketing goals by constructing specific identities for female consumers. Therefore, this study aims to figure out identities constructed through cosmetics advertisements in China and the United States, compare and analyze the differences in ideology and value orientation between these two countries. Moreover, the study attempts to discuss motivation why Chinese and American advertisers construct these identities to improve female consumers' awareness to judge cosmetics advertisements.

\subsection{Cosmetics Advertising}

Linguistic researches on cosmetics advertising have been studied from various perspective including translation, corpus linguistics, systemic functional linguistics (SFL), pragmatic and so on. As for translation, researchers focus on translation strategy (Pan \& Hu, 2020), teleology (Yu, 2020) as well as eco-translatology (Cai, 2020). When it comes to corpus linguistic, studies are mainly about language features (Yang, 2020). For SFL, researchers pay attention to interpersonal meaning (Yu, 2020), conceptual function, and textual function (Deng, 2019) as well as multimodal discourse analysis (Luo, 2019). From the perspective of pragmatic, studies are related to cooperative principle (Li, 2019; He, 2018), persuasive function and pragmatic presupposition (Xiong, 2019), and politeness principle (Lin, 2014). At present, some researchers have found that cosmetics advertisers deliberately cater to consumers' demands for particular identities (Zhong, 2016), but there is no literature to analyze it further from the perspective of identity construction. Some scholars have studied the female image in cosmetics advertisements (Zhong, 2016; Ji, 2019), but they seldom analyze from the perspective of critical pragmatics. In order to fill the research gap, this paper introduces the pragmatic identity theory and explores the identity types and distribution constructed by cosmetics advertisers for potential consumers by collecting cosmetics advertisements in China and the United States. In addition, this paper also analyzes the motivation of cosmetics advertisers to construct a specific identity from the perspective of critical pragmatic analysis, so as to improve the correct cognition and judgment ability of cosmetics buyers to cosmetics advertisements.

\subsection{Critical Pragmatic Analysis}

Critical pragmatics was formally proposed by Danish scholar Jacob Mey (1993). It aims at the ideology and value orientation behind language use in social contexts, promotes appropriate social pragmatics, and reveals the problems behind language use such as power interference, social prejudice, fraud, and deception. Chinese scholar Chen (2009) systematically clarified the goals, objects, and research methods of critical pragmatics, and pointed out that pragmatics research not only needs to pay attention to the subjectivity and interpersonal meaning brought 
by language use in the social and cultural context, but also urgently study the social meaning brought about by the use of discourse in the public domain.

Critical pragmatics scholars pay attention to various topics, mainly involving power manipulation, prejudice, and discrimination in language use as well as fraud in social language. In terms of power manipulation, Han, Liu, and Deng (2020) conduct a comparative analysis of the verbal behavior of Sino-US diplomatic rejection, revealing how China and the US use language to manipulate power on the political stage and the ideology and value orientation behind it. Peng (2016) investigates implicit language power and proposes a pragmatic analysis framework suitable for the construction of the discourse power of disadvantaged speakers. As for discrimination in language use, researchers usually focus on gender (Mao and He, 2017), age (Liu, 2019), and country image (Wang and Shen, 2016). In terms of fraud in social language, scholars pay particular attention to fraud in advertising slogans, such as health care product advertising (Zhu, 2018), real estate advertising (Chen, 2018; Chen and Chen, 2012), tobacco advertising (Xu, 2005) and so on. Mastering consumers' aesthetic appeals and guiding consumers' value orientation are necessary conditions for occupying the consumer market. With the improvement of consumption power and women's socioeconomic status, cosmetics advertising has a large proportion in the field of advertising $(\mathrm{Yu}, 2020)$. Cosmetics advertisements mainly capture the attention of female consumers and highlight their demands through designed advertising slogans to achieve marketing purposes. At present, the analysis of cosmetics advertising identity construction from the perspective of critical pragmatics is still a blank, so this research will fill this gap. The following research questions guide this study:

1) What kinds of identities are constructed by advertisers for female consumers in China and the USA?

2) What means do advertisers use to construct these identities for potential female buyers?

3) What value orientations do these means reflect the advertisers' appeal to potential consumers?

\section{Methodology}

\subsection{Data Collection}

With the development of e-commerce and social media, online shopping has become a major consumption channel for consumers. In 2020, the sales volume of Double 11 shopping event hit a new high. TMALL (a famous online sales platform in China) sales exceeded 490 billion yuan, and Jingdong (a famous online sales platform in China) sales exceeded 270 billion yuan. Thus, online cosmetics advertisements are selected as data of this research. Advertising in Chinese and English from eight high-end cosmetics brands, including Estee Lauder and Dior for Chinese and American consumers are chosen as data. The present study decides to focus on data collected from Weibo and WeChat official account, which are two of the most popular media for computer-mediated communication (CMC) in China. For collecting American advertising, the study focuses on Instagram and official website in English. According to Weibo, WeChat official account, Instagram as well as official website, 282 advertisements are collected from January to December 2019. After analysis, 120 advertisements related to identity construction were selected for further study.

If the advertisement directly or indirectly depicts the identity of the female consumer, the advertisement will be identified as an advertisement related to identity construction, the examples are as follow:

(1) Every woman can be beautiful!

(2) 我们才是掌控一切的人。(We are the people who control everything.)

（3）假若女性主宰世界会怎么样? (What if women dominate the world?)

If the advertisement only emphasizes the function or quality of the product itself, it is not regarded as an advertisement related to identity construction, the examples are as follow:

(4) Whether you're looking for trend products or classics and basics, our makeup selection has it all.

(5) More summer fun with many popping colors!

(6) 高级经典包装, 彰显魅力格调。(Advanced classic packaging, highlighting the charm of the style.)

\subsection{Data Analysis}

In this study, the inductive method and statistical method are used to analyze corpus. With regard to the inductive method, this study identifies and summarizes different kinds of identities by advertisers for potential female consumers from the content of cosmetics advertising discourse. In previous studies, woman has been portrayed as a young lady (Zhong, 2016), charming lady (Chen, 2014), individuality (Ji, 2019) and so on in advertisements. This study classifies the collected advertising corpus by referring to the previous researches. Table 1 shows the identity types and the definitions of the classifications in the corpus collected. This study classifies the identity 
construction types of advertisements from both external and internal aspects. As for appearance, advertisers construct two identities for female consumers, namely charming lady and forever-young lady. As for personality, advertisers construct four identities for female consumers, namely powerful lady, perfectionist, individuality as well as nature-lover.

Table 1. Working definitions of different kinds of identities

\begin{tabular}{ll}
\hline Identities & Working Definitions \\
\hline Appearance & \\
\hline Charming lady & $\begin{array}{l}\text { a. Advertisements that describe female's external beauty. } \\
\text { b. Advertisements that imply that consumers can be beautiful and attractive if they use the } \\
\text { product. }\end{array}$ \\
\hline $\begin{array}{l}\text { Forever-young } \\
\text { lady }\end{array}$ & $\begin{array}{l}\text { a. Advertisements that imply that consumers can be young if they use the product. } \\
\text { b. Advertisements that imply that consumers will look younger for their age after using } \\
\text { the product. }\end{array}$ \\
\hline Personality & $\begin{array}{l}\text { a. Advertisements that suggest that woman should dominate the world. } \\
\text { b. Advertisements that describe woman as a queen in her field. }\end{array}$ \\
\hline Perfectionist & $\begin{array}{l}\text { a. Advertisements that depict lady in pursuit of perfection. } \\
\text { b. Advertisements that suggest that lady should be perfect. } \\
\text { c. Advertisements that suggest that lady can be perfectionist by using cosmetics. }\end{array}$ \\
\hline Individuality & $\begin{array}{l}\text { a. Advertisements that describe that women should live for themselves. } \\
\text { b. Advertisements that describe that women don't care what other people think. } \\
\text { c. Advertisements that describe that women should achieve their personal value. }\end{array}$ \\
\hline Nature-lover & $\begin{array}{l}\text { a. Advertisements that describe/ imply a lady's love of nature. } \\
\text { b. Advertisements that describe/imply that lady prefers to use cosmetics that contain } \\
\text { natural ingredients. }\end{array}$ \\
\hline
\end{tabular}

After completing the statistics of various identity categories, this study will comment on the types, distribution, and construction means of the identity of potential female buyers in the advertisements combined with the mainstream values of the current society and the purpose of cosmetics advertising, and reveal how they achieve the purpose of marketing by catering to the value orientation of potential consumers.

\section{Results}

This section analyses identities' types and distributions as well as means to construct identities quantitatively by displaying the frequencies and percentages of different identities in China and America, and qualitatively by examining representative advertisements.

\subsection{Categories of Identities and Distributions}

Table 2. Identities in the US cosmetics advertising

\begin{tabular}{lrr}
\hline \multicolumn{1}{c}{ Identities } & Amount & Frequency \\
\hline Appearance & & \\
Charming lady & 29 & $49.15 \%$ \\
Forever-young lady & 5 & $8.47 \%$ \\
\hline Personality & & \\
\hline Powerful lady & 4 & $6.78 \%$ \\
Perfectionist & 16 & $27.12 \%$ \\
Individuality & 3 & $5.09 \%$ \\
Nature-lover & 2 & $3.39 \%$ \\
Total & 59 & $100.00 \%$ \\
\hline
\end{tabular}


The top two identities that American advertisers prefer to construct for female customers are charming lady (49.15\%) and perfectionist (27.12\%). As a result, American advertisers believe that the most desirable status for American women is a charming lady and perfectionist. On the contrary, forever-young lady, powerful lady, individuality, and nature-lover account for a very low proportion.

Table 3. Identities in Chinese cosmetics advertising

\begin{tabular}{lrr}
\hline \multicolumn{1}{c}{ Identities } & Amount & Frequency \\
\hline Appearance & & \\
Charming lady & 8 & $13.12 \%$ \\
Forever-young lady & 18 & $29.51 \%$ \\
\hline Personality & & \\
\hline Powerful lady & 12 & $19.67 \%$ \\
Perfectionist & 9 & $14.75 \%$ \\
Individuality & 10 & $16.39 \%$ \\
Nature-lover & 4 & $6.56 \%$ \\
Total & 61 & $100.00 \%$ \\
\hline
\end{tabular}

For the eight cosmetics brands mentioned above, the proportions of identity construction by Chinese advertisers for female consumers are different from America's. Forever-young lady (29.51\%) is the top identity constructed in China cosmetics advertising and it is followed by powerful lady (19.67\%) and individuality (16.39\%).

The above two tables show all identities embodied in 120 advertisements, which are classified into 6 types from the perspective of appearance and personality. The following section will show specific examples of each type.

\subsubsection{Charming Lady}

(1) Every woman can be beautiful!

(2) It's your turn to be a beauty star.

(3) 聚焦吸引力, 释放宝藏魅力。

(Focus on attraction and show the precious charm.)

(4) 自带女神光环, 低调吸睛。

(Catch eyes modestly with goddess's aura.)

Cosmetics advertisers construct the identity of charming lady for female customers according to their willingness to be attractive in their life. In example (1), American advertiser directly expresses that every woman has the opportunity to be beautiful, which implies that woman can be a charming lady.

In example (2), beauty star is a charming identity for a lady because beauty is a woman's nature. American advertiser uses this advertisement to suggest that consumers can become beauty stars if they use the product.

In example (3), Chinese advertiser uses 吸引力 (attraction) and 魅力 (charm) to build identity of charming lady for females.

In example (4), Chinese advertiser uses 女神 (goddess) to describe a woman as a charming lady. In China, women who are called 女神 are usually tall, slim with big eyes and a tall nose, attractive and charming.

\subsubsection{Forever-young Lady}

(5) Wake up more youthful-generating power.

(6) Skin looks more lifted, smoother. Feels firmer.

(7)不想老就不会老的精华。

(A serum that can help you keep young if you want to.)

(8) 只显年轻不显龄。

(Only make you look young instead of showing your age.)

In example (5), women can wake up their youthful energy after using the product. It means that if women own the product, they will have an identity of forever-young lady. 
In example (6), women are being implied for younger skin. If they use the product, they will have younger and firmer skin, which means that they look very young.

In example (7), female consumers can be young as they want. It seems that they can control their age by wearing make-up.

In example (8), advertiser makes consumers think that as long as they use the cosmetics, they will not let others know their actual age.

\subsubsection{Powerful Lady}

(9) Captivate the world with your power.

(10) Take control, you've got the power.

(11) 我们才是掌控一切的人。

(We are the people who control everything.)

(12) 假若女性主宰世界会怎么样?

(What if women dominate the world?)

In example (9) and (10), we can see that American advertisers inspire females directly that women should be powerful to conquer the world. Compared with eastern countries, American women emphasize more on equal rights in society, and they even want to get more opportunities to show their strength. Therefore, these two advertisements are very appealing to women.

In example (11), Chinese advertiser also stimulates women that they are the people who can control everything, which implies that women should have more right to make decision than men in society.

In example (12), the advertisement uses a special question to give female consumers imagination and expectation to be equal to men or even play a leading role in society.

\subsubsection{Perfectionist}

(13) Put your best face forward with our luxury eye, face, and lip makeup collections.

(14) Perfect your skin with the feel and finish you desire.

(15) 完美并不简单, 不停地旋转, 不停地练习同样的动作。肌肤也要完美。

(Perfection is not easy, keep spinning, keep practicing the same moves. Skin needs to be perfect too.)

(16) 女性追求至美。

(Women seek the best.)

In example (13) and (14), American advertisers construct a perfectionist identity for female consumer by encouraging them to perfect their eyes, faces, lips and skins. From the advertiser's point of view, in order to be a perfect person, you must have perfect skin and perfect facial features.

Example (15) is an advertisement spoken by Chinese actress Wu Jinyan. She plays a dancer in the advertisement. As a woman, she advocates that women should perfect their skin as seriously as practicing dancing like her. It is obvious that the advertisement makes good use of the effect of star. Star's perfect look can help consumers to understand the function of the product more directly.

In example (16), Chinese advertisers directly construct perfectionist for females by showing women's pursuit for the best.

4.1.5 Individuality

(17) We have color. You have the attitude.

(18) 我, 拒绝定义。我, 不止一面。

(I, refuse to be defined. There is more than one side in me.)

(19) 女性在社会上的价值不是成为一个母亲, 而是成为自己。

(The value of a woman in society is not to be a mother, but to be herself.)

(20) 忠于自我, 不被定义标签左右, 成就自己的价值。

(To be true to yourself, not to be controlled by labels, to achieve your own values.) 
From the above examples, it is found that individuality both appears in Chinese and American cosmetic advertising. However, the sense of individuality is much stronger in Chinese advertising than in American.

In example (17), the advertiser widely believes that women should have the attitude. Cosmetics companies can offer lipstick in a variety of colors and hope that consumers will reflect their special features after the lipstick on the picture.

In example (18), the Chinese advertiser uses the first person to urge that female consumers should reject oldfashioned images and become what they like. The use of the first person can narrow the distance between advertisers and consumers, and improve consumers' acceptance of the slogan.

In example (19), the Chinese advertiser is calling on women to view their social values in a whole new light. In the past, Chinese society generally believed that the value of women lay in having children and taking good care of the family. But with the improvement of women's education and the shift of social values, the status of women has changed. The value of women should be reflected in the realization of their own dreams instead of only devoting themselves to their family.

In example (20), the advertiser emphasizes that women should be independent, respect their own values and not be influenced by worldly opinions. Through this slogan, advertiser tries to construct an identity of individuality for female consumers.

\subsubsection{Nature-lover}

(21) It's about being inspired by nature.

(22) Nature is style.

(23) 走进自然, 体会万物正能量, 放松舒缓, 遇见更好的自己。

(Go into nature, experience the positive energy of all things, relax, and meet a better self.)

Both Chinese and American cosmetic advertisers construct female consumer's identity as a nature-lover by describing or implying the lady's love of nature or the lady's preference to use cosmetics that contain natural ingredients.

In example (21), American advertiser has described how women can be inspired by natural power when using cosmetics.

In example (22), American advertiser suggests that loving nature is a wonderful lifestyle. It implies that female consumers can have such a lifestyle and become nature-lovers after using cosmetics containing natural substances.

In example (23), Chinses advertiser gives consumers a picture of nature. When women use products, it seems that they can walk into nature and feel the power of nature. By being close to nature, they can feel relaxed and become better people.

\subsection{Means to Construct Identities}

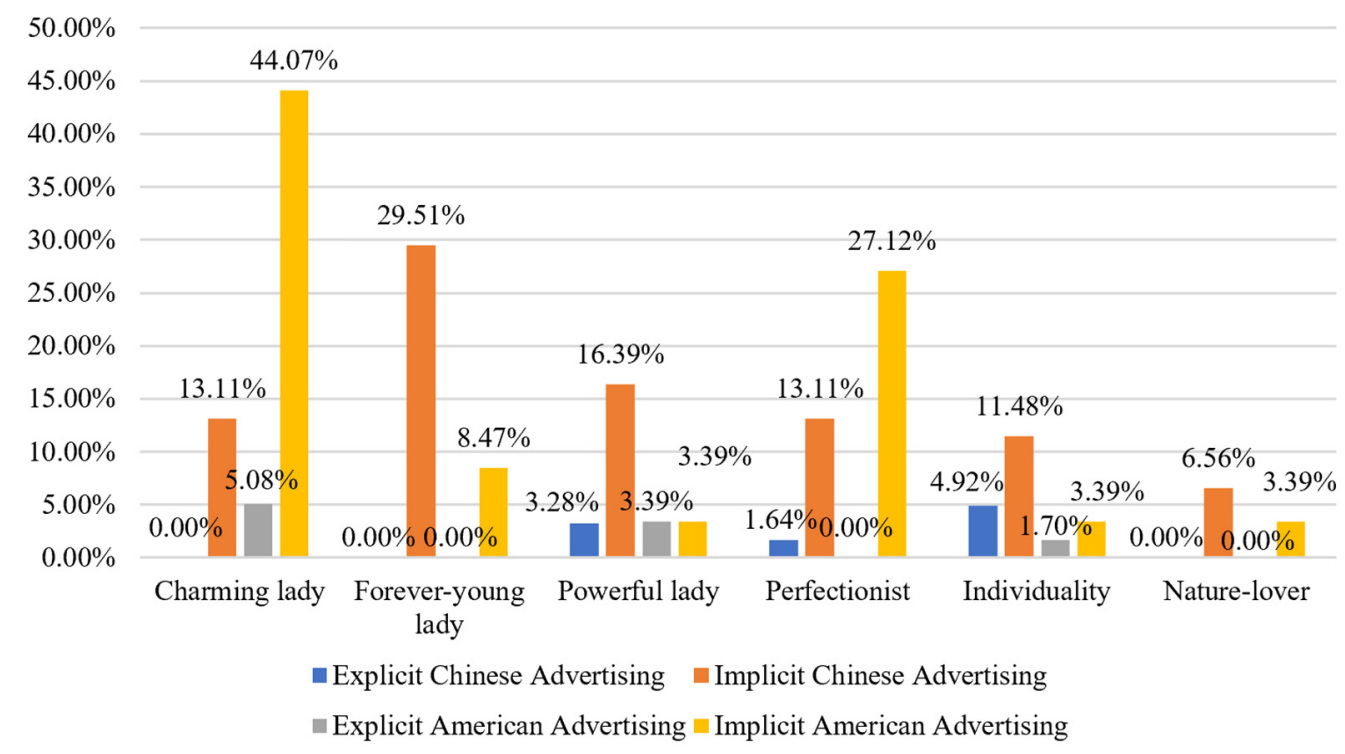

Figure 1. Percentage (\%) of explicit and implicit advertising in China and America 
Figure 1 above shows the percentage of explicit advertising and implicit advertising in China as well as America. In Chinese advertisements, explicit advertising accounts for $9.84 \%$ and implicit advertising accounts for $90.16 \%$. In American advertisements, explicit advertising accounts for $10.17 \%$ while implicit advertising accounts for $89.83 \%$. It is obvious that both Chinese and American advertisers prefer to use implicit way to construct identities for female consumers.

\subsubsection{Explicit Means}

Explicit means is an approach that cosmetics advertisers directly construct identity for female consumers by using specific identity, such as 掌控一切的人 (people who control everything), 母亲 (mother) and beauty star. Through corpus analysis, it can be known that the explicit means adopted by advertisers to construct the identity for potential female consumers is mainly to directly point out the roles of women, as shown in example (11) 我们 才是掌控一切的人。(We are the people who control everything) and example (19) 女性在社会上的价值不是 成为一个母亲, 而是成为自己。(The value of a woman in society is not to be a mother, but to be herself). In general, there are few cases where explicit methods are used. In explicit advertising, advertisers usually use "You are" and "We are" to construct identities for female consumers directly.

\subsubsection{Implicit Means}

Implicit means is an approach that cosmetic advertisers use suggestive words to indirectly tell female consumers that if they use the product, they will have a corresponding identity. The implicit means used by advertisers to construct the identity for female consumers mainly includes presupposition means and indirect means. In example (1), advertisers assume that female consumers can become beautiful after using cosmetics, so as to cater to the ideal image of consumers. In example (7) 不想老就不会老的精华(A serum that can help you keep young if you want to) and example (8) 只显年轻不显龄(Only make you look young instead of showing your age), advertisers imply indirectly that consumers can stay young forever if they use cosmetics.

\section{Discussion}

From the perspective of critical pragmatics, the motivation of advertisers to construct these identities for potential female consumers is to meet the psychological needs of consumers. The proportion of different identities by Chinese and American advertisers reflects the value orientation of women in different countries. The proportion of charming lady (49.15\%) and perfectionist (16\%) constructed by advertisers in the United States is much higher than in China. To some extent, it suggests that American advertisers value the attractiveness of women's physical appearance. On the contrary, the proportion of forever-young lady (18\%) constructed by advertisers in China is much higher than in America (5\%). It reflects that age is more important than facial features in Chinese women's values. In China, women over 30 years old are very sensitive about their age. This is because, in Chinese society, the value of a woman will decline after the age of 30. If a woman is unmarried and has no children by the age of 30 , her parents and friends will be very anxious. Therefore, the woman will be asked to participate in a blind date again and again until she marries her Mr. Right. In order to look younger, women will try their best to maintain their skin so that no one can know their actual age by seeing their appearances. Chinese advertisers have recognized women's needs, so they construct a forever-young identity for Chinese female consumers and make Chinese women more eager to buy the products. When it comes to personality, Chinese advertisers focus more on powerful lady (19.67\%) and individuality (16.39\%) because of the equality turn in China. According to Hofstede's cultural dimensions theory, China is a country with high power distance and masculinity. However, with the development of society, the status of Chinese women is gradually improved, and they are more eager to get the same power as men in society. Therefore, advertisers emphasize women's power and independence more in their advertisements. In terms of gender equality, the United States developed earlier than China, so the awareness of women's rights in American advertisements is relatively strong enough. By contrast, American advertisers' emphasis on the status of women is less intense than in China. As for nature-lover, the relative lack of references to this identity in Chinese advertisements (6.56\%) and American advertisements (3.39\%) partly reflects the low level of love for nature among female consumers in both countries. To sum up, cosmetics advertisers have purposes in constructing different identities for their female consumers in their advertisements. These aims are reflected in the following three aspects: firstly, marketing aims are achieved by catering to the identity demands of female consumers; Secondly, the constructed identities cater to some mainstream values of contemporary American and Chinese society respectively; Thirdly, these identities are constructed mainly through implicit means to make potential consumers willing to buy. Female consumers should think twice before buying cosmetics.

\section{Conclusion}

This study contrastively analyzes identity construction of female consumers in Chinese and American cosmetics advertisements through critical pragmatic analysis. Critical pragmatic analysis provides a new perspective for 
study on identity construction in cosmetics advertising. It is found that Chinese and American cosmetics advertisers do presuppose female consumers' identities in advertisements. Based on 120 cosmetics advertisements collected from Chinese and American social media, 6 types of identities are summarized from the perspective of critical pragmatic analysis. The identities are as follows: charming lady, forever-young lady, powerful lady, perfectionist, individuality as well as nature-lover. American advertisers prefer to construct charming lady and perfectionist for American women while Chinese advertisers tend to construct forever-young lady, powerful lady and individuality for Chinese women. Advertisers in the United States and China tend to use implicit means to construct consumer identities, which can give women the identities they want so as to stimulate consumption desire. From the perspective of motivation, cosmetics advertisers mainly use implicit means to meet the psychological needs of female consumers (such as beautiful appearance, youth and equality between men and women) to achieve the purpose of promoting products. Advertisers control consumers' ideology by responding to their psychological needs. Female consumers should consider the quality and reputation of cosmetics rather than advertisements before consumption. This study makes a critical pragmatic analysis of cosmetic advertisements in China and America, which can provide some references for the future critical research on identity construction.

\section{References}

Bamberg, M., De Fina, A., \& Schiffrin, D. (2007). Selves and Identities in Narrative and Discourse. Amsterdam: John Benjamins Publishing Company. https://doi.org/10.1075/sin.9

Cai, H. (2020). Sheng tai fan yi xue shi jiao de hua zhuang pin guang gao wen ben fen xi [Text Analysis of Cosmetic Advertisements from the Perspective of Ecological Translation Studies]. Modern Communication, (09), 104105.

Chen, L. L. (2014). Jie du hua zhuang pin zhong de nv xing xing xiang [Interpretation of Female Images in Cosmetics Advertising]. The Science Education Article Collects, (07), 142-143.

Chen, X. R. (2004). Lun yu yong ping heng [The Balance of Pragmatic]. Foreign Language Research, (06), 4247+112. https://dx.doi.org/10.16263/j.cnki.23-1071/h.2004.06.007

Chen, X. R. (2009). Pi ping yu yong xue: mu biao dui xiang yu fang fa [Critical Pragmatics: Target Objects and Methods]. Foreign Language and Their Teaching, (12).

Chen, X. R. (2013). Yu yong shen fen: dong tai xuan ze yu hua yu jian gou [Pragmatic Identity: Dynamic Selection and Discourse Construction]. Foreign Languages Research, (04), 27-32+112. https://dx.doi.org/10.13978/j.cnki.wyyj.2013.04.009

Chen, X. R. (2014). Yu yong xue shi jiao xia de shen fen yan jiu-guan jian wen ti yu zhu yao lu jing [The Study of Identity from the perspective of Pragmatics-Key issues and Main Approaches]. Modern Foreign Languages, (05), 702-710+731.

Chen, X. R. (2018a). Shang ye guang gao shen fen tao lu de pi ping yu yong fen xi [A Critical Pragmatic Analysis of Identity Trap in Commercial Advertisements]. Shandong Foreign Language Teaching, (05), 24-33. https://doi.org/10.16482/j.sdwy37-1026.2018-05-003

Chen, X. R. (2018b). Yu yong shen fen lun: ru he yong shen fen hua yu zuo shi [Pragmatic Identity theory: How to Do Things with identity Discourse.]. Beijing: Beijing Normal University Publishing House.

Chen, X. R., \& Chen, J. (2012). Mo hu xing shang ye guang gao yong yu de pi ping yu yong fen xi-yi fang chan guang gao yong yu wei li [A Critical Pragmatic Analysis of Ambiguous Commercial Advertising Terms-A Case study of Real estate Advertising Terms]. Foreign Language and Literature Studies, (04), 235242+279+288. https://doi.org/10.19716/j.1672-4720.2012.04.002

Deng, X. (2019). Hua zhuang pin guang gao yu pian de chun li gong neng fen xi-yi SK-II xin lang guan fang wei bo wei li [The Functional Analysis of Cosmetics Advertising Texts-Taking SK-IIas Example]. Overseas English, (12),83-84+91.

Han, D., Liu, F. G. \& Deng, Y. C. (2020). Pi ping yu yong shi jue xia zhong mei wai jiao ju jue yan yu xing wei dui bi yan jiu [The Pragmatic Criticism Focuses on the Comparative Study of Chinese and American Diplomatic Refusal Speech Acts]. Foreign Languages Research, (01), 19-24. https://doi.org/10.13978/j.cnki.wyyj.2020.01.004

He, X. (2018). Yu yong xue shi jiao xia hua zhuang pin guang gao yu yu zhi liang zhun ze de chong tu [The Conflict between Cosmetics Slogan and Quality Criterion from the Perspective of Pragmatics]. Journal of Jinzhou Medical University (Social Science Edition), (02), 142-144. https://doi.org/10.13847/j.cnki.lnmu(sse).2018.02.038 
Ji, J. (2019). Qian tan hua zhuang pin guang gao zhong nv xing xing xiang de bian yu bu bian yi bai que ling guang gao wei li [On the Change and Invariability of Female Image in Cosmetics Advertisement-Taking SPDC's Advertisement as An Example]. Da zhong wen yi[Popular Literature], (15),186-187.

Kroskrity, P. V. (1999). Identify. Journal of Linguistic Anthropology, (9). https://doi.org/10.1525/jlin.1999.9.12.111

Li, M. Q. (2019). Hua zhuang pin guang gao biao yu Zhong wei fan he zuo yuan ze de yu yong fen xi [Pragmatic Analysis of the violation of the Cooperative Principle in cosmetics advertising slogans]. Read and Write Periodical, (07), 9-10+4. https://doi.org/10.16071/j.cnki.cn51-1650/g4.2019.07.006

Lin, S. Q. (2014). Li mao yuan ze shi yu xia ren cheng zhi shi pian li de yu yong yi yi-hua zhuang pin guang gao yu pian jie du [The pragmatic meaning of personal deference from the perspective of politeness principle]. Journal of Liaoning Technical University (Social Science Edition), (03),299-302.

Liu, K. (2019). Pi ping yu yong xue shi jiao xia 90 hou qun ti xing xiang su zao yan jiu [A Study on the Image building of post-90s Group from the perspective of Critical Pragmatics]. Journal of Shanxi Youth Vocational College, (01), 9-11+33.

Luo, C. (2019). Zhong ying hua zhuang pin guang gao de duo mo tai hu ayu dui bi fen xi [A Comparative Analysis of Multimodal Discourses in Chinese and English Cosmetics Advertisements]. [Master Dissertation, Guangdong University of Foreign Studies].

Mao, D. S., \& He, G. (2017). Wang luo shi da inv xing jing xiang de yi shi xing tai pi ping: ji yu wen hua yu yong xue shi jiao [Ideological Criticism of Female Mirror Image in the Network Era: Based on the Perspective of cultural Pragmatics]. Journal of Shenzhen University (Humanities \& Social Sciences), (05), 134-138+147.

Mey, J. (1993). Pragmatics: An Introduction. Oxford: Blackwell. https://doi.org/10.1016/0378-2166(93)90041-M

Pan, Y. F., \& Hu, Y. N. (2020). Hua zhuang pin guang gao yu de ying yi han ce lue [The Strategy of Translating Cosmetics Advertising Slogans into Chinese]. Wen jiao zi liao[Cultural and Educational Information], (20), 221-223.

Peng, Y. (2016). Pi ping yu yong xue shi jiao xia de yin xing hua yu quan li jian gou yan jiu [Research on the Construction of implicit Discourse Power from the perspective of Critical Pragmatics]. Journal of Guangdong University of Foreign Studies, (03), 58-65.

Wang, J. L. Shen, Z.Q. (2016). Yu yong yu she yu xiang gao ren shen fen de hua yu gou jian ji yu hui gui qian hou xiang gang zheng fu shi zheng bao gao de pi ping xing fen xi [Pragmatic Presupposition and Discourse Construction of Hong Kong Identity-Based on A Critical Analysis of The Policy Address of the Hong Kong Government before and after the Handover]. Journal of Tianjin Foreign Studies University, (05), 13-17+80.

Xiong, L. X. (2019). Yu yong yu she shi jiao xia Facebook Zhong hua zhuang pin guang gao ying xiao hua yu quan shuo gong neng de yan jiu [Research on Persuasion Function of Cosmetics Advertising Marketing Discourse in Facebook from the perspective of Pragmatic Presupposition]. [Master Dissertation, Guangdong University of Foreign Studies].

$\mathrm{Xu}$, J. H. (2005). Jin nian wo guo yan cao guang gao yu yong ce lue de pi ping [Criticism of the Pragmatic Strategies of Tobacco Advertising in China in Recent Years]. Contemporary Rhetoric, (01), 25-27.

Yang, S. (2020). Ji yu yu liao ku de ying wen hua zhuang pin guang gao yu yan te dian yan jiu [A Study on the Linguistic Characteristics of English Cosmetics Advertising Based on Corpus]. Knowledge Economy, (21), 48+54. https://doi.org/10.15880/j.cnki.zsjj.2020.21.023

Yu, H. H. (2020). Gong neng yu fa shi jiao xia hua zhuang pin guang gao de ren ji yi yi fen xi [Interpersonal Meaning analysis of Cosmetic Advertisements from the Perspective of Functional Grammar]. Youth Literator, (03), 192.

Yu, X. C. (2020). Mu di lun shi jiao xia hua zhuang pin guang gao de fan yi [The Translation of Cosmetic Advertisements from the Perspective of Skopos Theory]. Research on Transmission Competence, (17), 9596.

Zhong, H. (2016). Zhong ying hua zhuang pin guang gao yu zhong de yu yong yu she fen xi [Pragmatic Presupposition Analysis of Chinese and English Cosmetics Advertising Slogans]. Overseas English, (16), 210-211.

Zhu, J. L. (2018). Bao jian shi pin guang gao yu zhong de yu yong mo hu yu pi ping xing fen xi [Pragmatic Ambiguity and Critical Analysis in Health Food Advertising Slogans.]. Nanjing Institute of Industry 
Technology, (04), 48-51+55. https://doi.org/10.15903/j.cnki.jniit.2018.04.013

\section{Copyrights}

Copyright for this article is retained by the author(s), with first publication rights granted to the journal.

This is an open-access article distributed under the terms and conditions of the Creative Commons Attribution license (http://creativecommons.org/licenses/by/4.0/). 